\title{
Impact of the Relief on the Territorial Distribution of the Precipitations on the Example of Samtskhe-Javakheti Region
}

\author{
Lamzira Lagidze ${ }^{1}$, Vazha Trapaidze ${ }^{2}$, Besik Kalandadze ${ }^{3}$ \\ ${ }^{1}$ Dept. of Nature Use Management, Ivane Javakhishvili Tbilisi State University, Tbilisi, Georgia \\ ${ }^{2}$ Dept. of Hydro-Meteorology, Ivane Javakhishvili Tbilisi State University, Tbilisi, Georgia \\ ${ }^{3}$ Dept. of Soil Geography, Ivane Javakhishvili Tbilisi State University, Tbilisi, Georgia \\ Email address: \\ lagidze_1@rocketmail.com (L. Lagidze), trapaidze@yahoo.com (V. Trapaidze), b.kalandadze@tsu.ge (B. Kalandadze)
}

\section{To cite this article:}

Lamzira Lagidze, Vazha Trapaidze, Besik Kalandadze. Impact of the Relief on the Territorial Distribution of the Precipitations on the Example of Samtskhe-Javakheti Region. Earth Sciences. Special Issue: Modern Problems of Geography and Anthropology.

Vol. 4, No. 5-1, 2015, pp. 91-98. doi: 10.11648/j.earth.s.2015040501.27

\begin{abstract}
The climatic conditions in Samtskhe-Javakheti region differ from those in other regions of Georgia. The major reason for the diversified climate in the region is the nature of the underlying surface and altitude above from the sea level (900-3,300 m), nature of the surface jointing, alteration of ridges and valleys, vegetation cover (forest, meadow, valley, water basins) causing unequal warming of the underlying surface and intensification of the circulation processes. The vegetation cover in the region is transformed intensely under the influence of the anthropogenic factors what drastically changes the climatic conditions. Atmospheric precipitations are one of the climate-forming factors having its influence on the climate and determining the degree of humidification. The annual amount of atmospheric precipitations on the territory of Samtskhe-Javakheti varies between 400 and $1400 \mathrm{~mm}$. It is minimal on Javakheti Plateau and Akhaltsikhe basin. The amount of precipitations on Javakheti Plateau first decreases and then, increases gradually at higher altitudes. In the basin of the river Paravani, at 1,400 $\mathrm{m}$ asl, the amount of precipitations decreases by $6-17 \mathrm{~mm}$ on average after each $100 \mathrm{~m}$ altitude, while above $1400 \mathrm{~m}$ asl, increases first, slightly (by 4-20 mm) and then, significantly (by 44-76 mm after each $100 \mathrm{~m}$ ). The maximum amount of precipitations fallen in the area in one month in the cold period of the year is $202 \mathrm{~mm}$, and the least amount is $0.1 \mathrm{~mm}$. The distribution of precipitation on the territory of Samtskhe-Javakheti changes depending on the altitude, and at lower elevations, the amount of liquid precipitations is $75 \%, 18 \%$ are hard precipitations and $8 \%$ are mixed ones, while in the high-mountainous zone, these indicators are $60 \%, 31 \%$ and $9 \%$, respectively. A decisive role in the territorial distribution of precipitations is played by the relief forms. The region is bordered by high ridges from all its sides. The ridges transform the atmospheric circulation processes and hamper a free flow of air masses. Therefore, the air masses in the region are of a descending nature, with the amount of moisture reduced in it (the condensation is limited), and as a result, the amount of precipitations on the major territory of Samtskhe-Javakheti is little. A continental type of the annual distribution of precipitations dominates all over the territory of the given region.
\end{abstract}

Keywords: Samtskhe-Javakheti, Relief, Precipitations, Synoptical Processes

\section{Introduction}

At the modern stage, by considering the influence on the climate formation, the problem of the impact the mankind exerts on the environment is very important. In the future, this problem may become a reason for further progress of the undesirable phenomena or degradation. Georgia with its complex physical-geographical conditions (the altitude of the country above sea level is $0-5068 \mathrm{~m}$ ), is considered a classical example of a mountainous country with diversified climatic conditions [1]. In this respect, Samtskhe-Javakheti, one of the most important regions of Georgia, is outstanding. The region is found in the south of the country and its climate drastically differs from the rest of the country (this is due to the influence of local factors). Samtskhe-Javakheti is bordered by high ridges from all its sides. The ridges change the general atmospheric circulation developed in Georgia. The meridian-like position of the ridges weaken the impact of the large-scale circulation processes of the atmosphere developed on the Trans-Caucasian territory and significantly intensify 
the impact of the complex local orographic factors (uplands, plateaus, basins) [2].

In different regions of Samtskhe-Javakheti, both, the climatic and natural conditions are much different, and even the natural and climatic conditions in Samtskhe and Javakheti are different. Javakheti, with its hypsometric development and vegetation cover, has quite a Continental climate. The conditions in the settled areas in valleys and Akhalkalaki plateau are somewhat different, with different economic branches developed in the past in terms of warm climatic conditions and owing to the terrace system [3].

The leading branch in the region is agriculture. It is known that climate is one of the most important natural components for agriculture. Therefore, assessment of the climate in the region is very important to rationally use the climatic conditions of the region [4].

Samtskhe-Javakheti region is distinguished in a recreational respect, too. There are various resorts here: mountain-skiing (Bakuriani), recreational-curative (Likani), mineral waters (Borjomi). Therefore, the study of this region is particularly important on the background of climate change.

\section{Factors determining precipitation}

\subsection{Atmospheric Circulation Processes Forming the Climate}

The climate-formation process in Georgia is influenced by the meridian circulation of air masses - the penetration of moderate, tropical and sometimes, polar (boreal) air masses, while the air masses from the moderate latitudes are most common. They are saturated with moisture as they flow from the west. Penetration of tropical air masses is frequent, and they form hot and dry weather [5].

The weather conditions in Samtskhe-Javakheti region greatly differ from those in other parts of Georgia as a result of the local factors. The penetration of air masses from the south is not infrequent either. As a result, the content of water vapor in air masses in case of north movement decreases gradually under the influence of numerous ridges, and the amount of the precipitations produced is not great. Besides, the nature of Samtskhe-Javakheti territory (basin, plateau) promotes cooling the lower air layers in winter and developing strong convectional processes in the summer resulting in short downpours, thunder and lightning and hail.

Synoptical processes promoting the penetration of air masses to the South Caucasus and territory of Georgia, in particular, are of four major types: 1) western, 2) eastern, 3) anticyclone state, and 4) wave agitations developed in the south regions of the South Caucasus [5].

In addition to these major processes, a double penetration of air masses to Georgia also forms the climate in the country, in particular, the transfer of the warm front from south-west and convectional processes. The latter are mostly typical to the warm period of the year. In Samtskhe-Javakheti, this process is particularly intense what is promoted by the peculiarity of the relief, in particular, the vast plateau of
Akhalkalaki lacking the vegetation and Akhaltsikhe basin.

These processes much differ from one another with the weather nature. In addition, their frequency and intensity change depending both, on the territory and seasons [6].

An important role in forming the weather in the Samtskhe -Javakheti region is played by the Western process. It is true that this process yields much less atmospheric precipitations than on the territory of west Georgia, but most of the precipitations falling during the year are resulted from them. This process results in the cloudy and wet weather on the territory of Samtskhe-Javakheti, particularly in its western part.

On the territory of Georgia, the western process is developed during the transfer of the cold front, Mediterranean cyclones and associated occlusive front. As a result of the resistance of the ridges west of Samtskhe-Javakheti, the transfer of fronts is hampered (i.e. their action is diminished), and they are much less intense when reaching the territory of Samtskhe-Javakheti. The amount of precipitation fallen in this region is much less than on the western slopes of the ridges. A great portion of the precipitations fallen during the year is the result of this process. Penetration of the Arctic air masses to Samtskhe-Javakheti from the west not only forms the precipitations, but also significantly reduces the air temperature. However, the cases of the temperature fall due to the penetration of Arctic air masses from the east are also possible [7].

Approximately $200 \mathrm{~mm}$ of the precipitation fallen on the territory of Samtskhe-Javakheti during the year are the result of the penetration of air masses from the west, as in summer the penetration of air masses from the west is frequent and besides, the local convectional processes are intensely developed. As a result of their interaction, the precipitation-forming processes are intensified resulting in abundant precipitations in this period.

A less important role in forming the weather and climate is played by the air penetration from the east. The influence is strong on Akhaltsikhe basin and Akhalkalaki k plateau.

The duration of the eastern process is 5-6 days on average, 10 days maximum and sometimes more.

The eastern process is more common in winter. The amount of precipitation is usually little, but intense precipitations are sometimes the case.

The eastern process is more intense in spring, as the instability of air masses and temperature of the underlying surface increase during this process helping the development of the convectional process.

The wave agitations developed in the south part of the South Caucasus form peculiar synoptic processes and typical weather conditions on the territory of Samtskhe-Javakheti, which are mostly double-sided, or are developed after the penetration of the air mass from the west is complete.

Often, the wave developed in the south shifts north-west and mostly, occludes on the territory of west Georgia. When this happens, abundant precipitations are fixed in south Georgia in the first instance. In summer, this process is often 
accompanied by thunder and lightning and hail and fog in winter.

This process is fixed in all seasons of the year, and it is more frequent and intense in the warm period, particularly in summer.

Approximately $150 \mathrm{~mm}$ of the precipitations falling in the region is resulted from the southern process, and sometimes with high intensity, lasting for several days. The duration of the process depends on the intensity of the air mass penetration.

Convectional processes have a major impact on the peculiarity of the climate in Samtskhe-Javakheti, and on the humidity regime in particular (due to the southern location of the region) having a major impact on the total amount and annual distribution of precipitations. These processes are characterized by abundant precipitations in short periods and local character. They usually cover large areas, but in summer, $30-40 \%$ of the precipitations are formed owing to these processes [8].

The analysis of the atmospheric circulation processes evidences that their action and intensity in the region vary in different seasons what determines the climatic peculiarities of the region in different seasons.

\subsection{Impact of the Underlying Surface (Relief) on the Precipitation Formation}

One of the reasons for the climatic diversity in Samtskhe-Javakheti area is the degree of surface jointing, alternation of ridges and valleys, vegetation cover (forest, meadow, valley), which absorb different amounts of sunray energy, i.e. they get warmed to different degrees. The location of the ridges change the atmospheric circulation processes so much that the weather conditions (precipitations, temperature, humidity and winds) in its lower layers are much different on the different sides of the ridges even in case of the same processes.

The climate on the territory is greatly influenced by orographic barriers. The mountainous area of Caucasioni plays an important role in forming the climate in the region. The relief hampers the penetration of the cold air masses from the north to the territory of south Caucasus and Samtskhe-Javakheti, respectively. Another important orographic barrier for Samtskhe-Javakheti is Arsiani and Ajara-Imereti ridges hampering the spread of the humid air masses from the west. Therefore, their windward slopes are characterized by abundant precipitations, and their downwind slopes, adjacent valleys and basins have little precipitations resulting in substantial climatic contrasts.

The absolute height of Samtskhe-Javakheti varies from 900 to $3300 \mathrm{~m}$ (Didi Abuli is found at $3300 \mathrm{~m}$ ). The territory of the region is uneven and its major part is high-mountainous. Therefore, the general atmospheric circulation is transformed to such a degree that a particular kind of cloudiness is formed.

The climatic peculiarities in the region much depend on the type of the vegetation cover. In terms of the Continental climate, the valley vegetation occupying the vast areas further supports the air dryness. Different climatic conditions are formed by an intense forest cover on the territory of Samtskhe, with large areas occupied by hardwood and coniferous forests [5].

\section{Distribution of Precipitations (Study Analysis)}

The annual amount of atmospheric precipitations on the territory of Samtskhe-Javakheti varies between 400 and 1400 mm. It is minimal on Javakheti Plateau and in Akhaltsikhe basin and is maximal in the high-mountainous zone of Ajara-Imereti and Arsiani ridges.

The amount of atmospheric precipitations in Samtskhe-Javakheti is less than in other regions of Georgia. The peculiar orographic conditions transform the circulation in the region in the way resulting in less precipitation in the area. A decisive role in the territorial distribution of precipitations is played by the relief forms. The region is bordered by high ridges from all sides. The ridges hamper the free movement of air masses. The movement of the air masses penetrated in the region is of a descending nature, and therefore, the amount of moisture is reduced here (the condensation is limited) and no abundant precipitations are formed. As a result, the amount of precipitations on the territory of Samtskhe-Javakheti is little.

Akhaltsikhe basin and the slopes of the ridges south and east of it have little precipitations. Average 500-700 $\mathrm{mm}$ of precipitations falls in the region annually (fig.1). The precipitations are more abundant on the slopes of Ajara-Imereti and Arsiani ridges, with average $1000 \mathrm{~mm}$ precipitations falling at the altitude of $1500 \mathrm{~m}$. The amount of precipitations increases with the height and reaches $1200-1400 \mathrm{~m}$ in the upper part. The southern part of Akhalkalaki Plateau is particularly poor in precipitations with the annual amount of precipitations of 500-600 mm. At higher altitudes, the amount of precipitations first reduces and then starts to increase insignificantly. For example, at 2,112 $\mathrm{m}$ asl, in Epremovka, the annual amount of precipitations is $722 \mathrm{~mm}$ (Table 1, fig. 2.). The amount of precipitations in the region is much lower than in any other area of Georgia at the same altitude. The climate here is particularly dry and therefore, there is a lack of forests. A continental type of the annual distribution of precipitations dominates all over the territory of the given region [Javakhishvili, 1981]. The least precipitations fall in winter, with the minimum value in January (24-62 mm) and most precipitations fall in summer, with the maximum value in June (73-116 mm). The second minimum is fixed in September $(34-55 \mathrm{~mm})$ and the second maximum is fixed in October (41-62 mm).

The amount of precipitations on Javakheti Plateau first decreases and then, increases gradually at higher altitudes. In the basin of the river Paravani, at 1,400 $\mathrm{m}$ asl, the amount of precipitations decreases by $6-17 \mathrm{~mm}$ on average after each $100 \mathrm{~m}$ altitude, while above $1400 \mathrm{~m}$ asl, increases first, slightly (by 4-20 mm) and then, significantly (by 44-76 mm 
after each $100 \mathrm{~m}$ ). (Quite frequently) In the study area, the amount of precipitations may be either less or more the norm. The maximum amount of precipitations fallen in the area in one month in the cold period of the year is $202 \mathrm{~mm}$, being three times more the norm in this period, and the least amount is $0.1 \mathrm{~mm}$ [9].
The amount of precipitations on the territory of Samtskhe-Javakheti in the warm period of the year varies from 380 to $621 \mathrm{~mm}$, and from 140 to $328 \mathrm{~mm}$ in the coldest period of the year. As these data suggest, the amount of precipitations in the warm period of the year is much more than the same amount in the coldest period of the year.



Figure 1. Distribution of atmospheric precipitations on the territory of Samtskhe-Javakheti.

Table 1. Annual distribution of precipitations depending on the average annual multi-year data, mm.

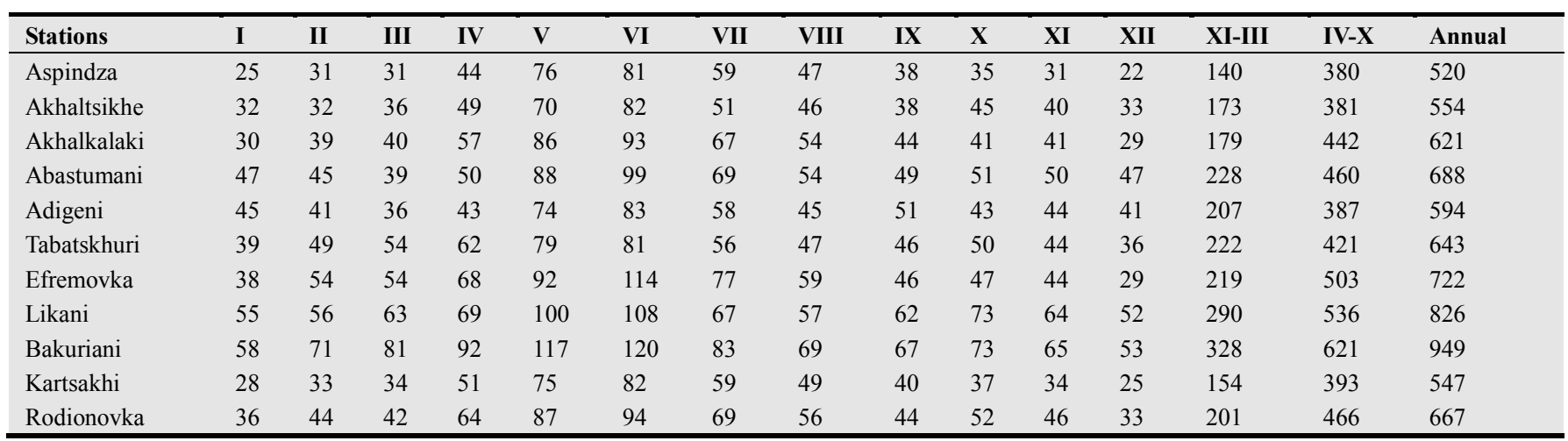




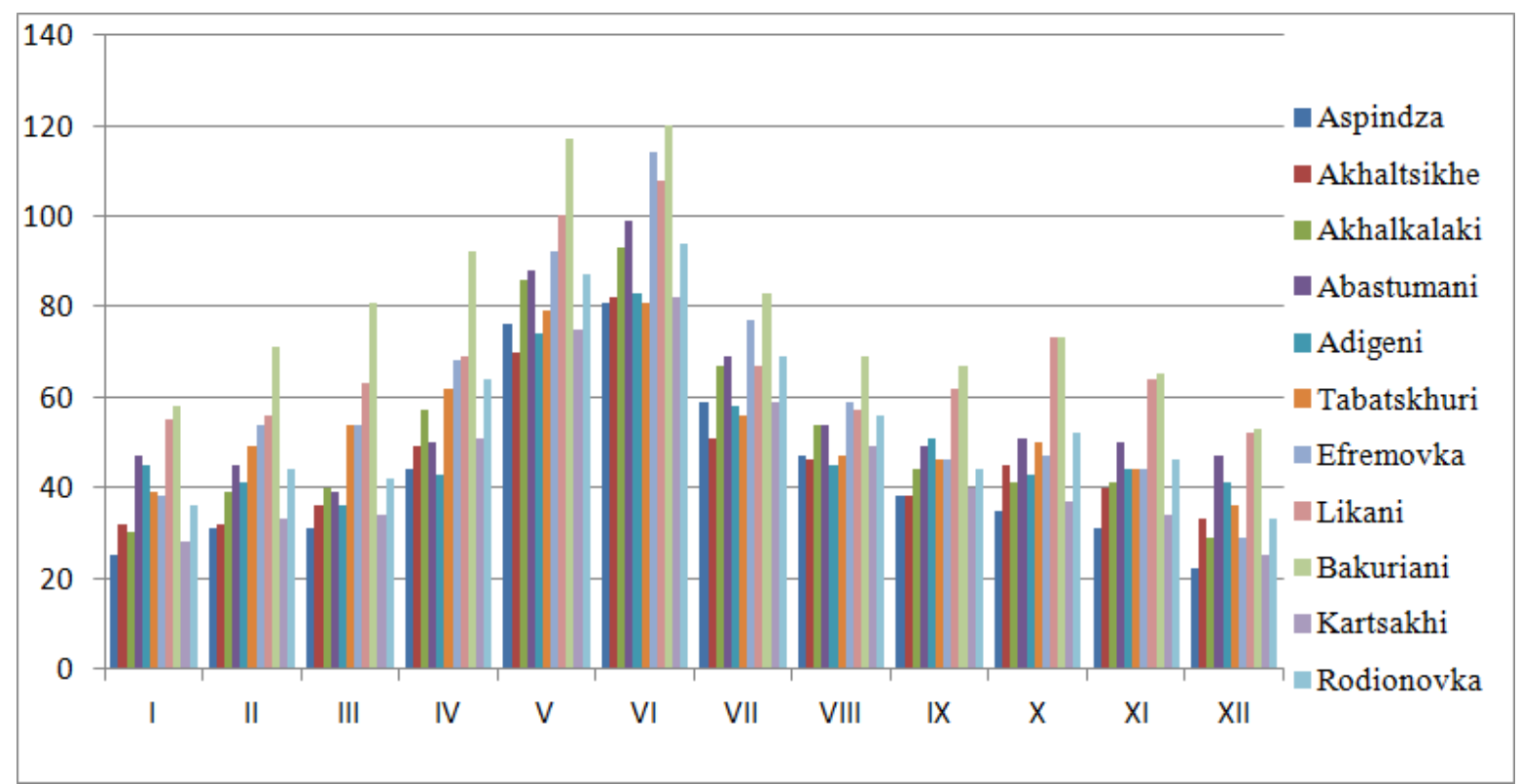

Figure 2. Annual distribution of atmospheric precipitations depending on average multi-year data on the territory of Samtskhe-Javakheti, mm.

The degree of the moisture accumulation in soil depends on the amount of precipitations fallen in the cold period of the year. The conditions of Samtskhe-Javakheti do not favor this process. However, this situation is somehow mitigated by much reduced evaporation from the soil and the water surface in the cold period, resulting in the increased productivity of the fallen precipitations, while in winter, due to low temperatures, the snow cover in the region is maintained for quite long. The precipitation productivity is the result of not only the general increase in the amount of precipitations, but also of the duration of time during which the precipitations are produced (Table 2). The duration of precipitations in summer is reduced by convectional processes with resultant short downpours. On the other hand, frequent cyclonic penetrations in the coldest period of the year much increase the duration of the precipitations.

For practical reasons, it is important to identify the amount of precipitations fallen at night and during the day what will allow identifying the effectiveness of precipitations (Table 3). Generally, the precipitations fallen at night are more effective than those fallen during the day. The territorial distribution of the precipitations fallen at night and during the day in the mountains is characterized by a number of peculiarities and depends on local conditions. In south Georgia, during the year and particularly, in the warm period of the year, the duration of the precipitations falling is much more during the day. At the same time, the duration of precipitations is more during the day than at night (Fig. 3.). This is the major reason causing the dryness and little precipitation effectiveness in the region. Certain regularity in the distribution of daily maximums of precipitations in Samtskhe-Javakheti is that the maximum daily precipitations in the warm periods are the result of the activated front processes promoted by local convectional processes.

The daily maximum of precipitations in SamtskheJavakheti is not very high, and is $55 \mathrm{~mm}$ as per the data of
Akhalkalaki, with its maximum value $(85 \mathrm{~mm})$ fixed in Abastumani what is much less the daily maximum registered in Georgia (355 mm). The number of days with precipitations in Samtskhe-Javakheti, despite the dry air in the region, is not few, and varies from 121 to 172 days a year depending on the area. The number of such days is great in the western part and above $2000 \mathrm{~m}$ asl. The maximum number of days with precipitations is fixed at the end of spring and at the beginning of summer (with the mean monthly value of 15-18 days) and the minimum number of days with precipitations is fixed in winter and at the end of summer (8-10 days). The duration of precipitations in the region is not long and varies between 500 and $1200 \mathrm{hrs}$. It is $200-500 \mathrm{hrs}$. in the warm period and $300-700 \mathrm{hrs}$. in the cold period with its maximum duration of 1200-2000 hrs. The maximum of continuous precipitations is fixed in January and December, and the minimum is fixed in the summer months.

The assessment of the abnormal distribution of precipitations in different months is important. The most and least monthly and annual amounts vary significantly, and the amount of precipitations in the mountain may be both, more or much less the norm. The probability of the amount of precipitations exceeding the norm is much less in the cold period of the year, while the same probability is more in the warm period of the year.

The distribution of precipitations changes at various altitudes, and at lower elevations, the amount of liquid precipitations is $75 \%, 18 \%$ are hard precipitations and $8 \%$ are mixed ones, while in the high-mountainous zone, these indicators are $60 \%, 31 \%$ and $9 \%$, respectively. In the mountainous zone, hard precipitations are expected all over the year and only from September to May at lower altitudes.

Snow. Snow is an important source for moisture to accumulate in the ground and of river alimentation. Snow has a major impact on the thermal regime of air and soil and on climate, consequently. A snow cover protects the winter crops 
against intense frosts and great temperature variation. It is a poor heat conductor, and as a result, the soil under the snow cover maintains high temperature. The height of a snow cover in western regions is great and it is durable in the eastern regions [10].

The dates of the appearance and disappearance of a snow cover are given based on the data for Abastumani (Table 4). The height of a snow cover in the first decade of February reaches its maximum, $31 \mathrm{~cm}$ on average (Table 5). In winter generally, the maximum height of a snow cover does not reach $1 \mathrm{~m}$. Particularly snowless are winters in the Akhaltsikhe basin (fig. 4.). The duration of a snow cover here is less than 1 month. As the average multiyear data suggest, the duration of a snow cover in Akhaltsikhe is 63 days, it is 69 days in Adigeni, 54 in Aspindza, 153 in Rodionovka, 101 in Akhalkalaki and 153 in Epremovka.

Table 2. Maximum duration of precipitations, hrs.

\begin{tabular}{|c|c|c|c|c|c|c|c|c|c|c|c|c|c|}
\hline Station & I & II & III & IV & $\mathbf{V}$ & VI & VII & VIII & IX & $\mathbf{X}$ & XI & XII & Annual \\
\hline Abastumani & 331 & 229 & 218 & 136 & 125 & 104 & 58 & 75 & 101 & 191 & 206 & 153 & 1927 \\
\hline Akhaltsikhe & 134 & 130 & 101 & 77 & 94 & 96 & 76 & 110 & 74 & 119 & 96 & 130 & 1237 \\
\hline Akhalkalaki & 130 & 154 & 183 & 172 & 112 & 88 & 90 & 52 & 56 & 120 & 180 & 112 & 1449 \\
\hline Bakuriani & 243 & 286 & 266 & 169 & 196 & 140 & 213 & 133 & 132 & 183 & 288 & 194 & 1580 \\
\hline
\end{tabular}

Table 3. Annual distribution of precipitations during the day and at night

\begin{tabular}{|c|c|c|c|c|c|c|c|c|c|c|c|c|c|c|}
\hline Stations & Day/Night & $\mathbf{I}$ & II & III & IV & $\mathbf{V}$ & VI & VII & VIII & IX & $\mathbf{X}$ & XI & XII & Annual \\
\hline \multirow{2}{*}{ Bakuriani } & Night & 30 & 33 & 32 & 30 & 40 & 34 & 32 & 26 & 32 & 34 & 25 & 20 & 368 \\
\hline & Day & 30 & 29 & 33 & 34 & 68 & 67 & 38 & 42 & 36 & 38 & 30 & 41 & 466 \\
\hline \multirow{2}{*}{ Akhaltsikhe } & Night & 16 & 15 & 18 & 21 & 27 & 25 & 16 & 21 & 20 & 24 & 17 & 14 & 239 \\
\hline & Day & 14 & 11 & 16 & 22 & 44 & 55 & 29 & 27 & 23 & 23 & 16 & 11 & 291 \\
\hline \multirow{2}{*}{ Akhalkalaki } & Night & 9 & 15 & 14 & 19 & 32 & 29 & 17 & 16 & 17 & 22 & 15 & 8 & 213 \\
\hline & Day & 10 & 11 & 11 & 22 & 51 & 55 & 32 & 38 & 24 & 20 & 15 & 8 & 297 \\
\hline
\end{tabular}

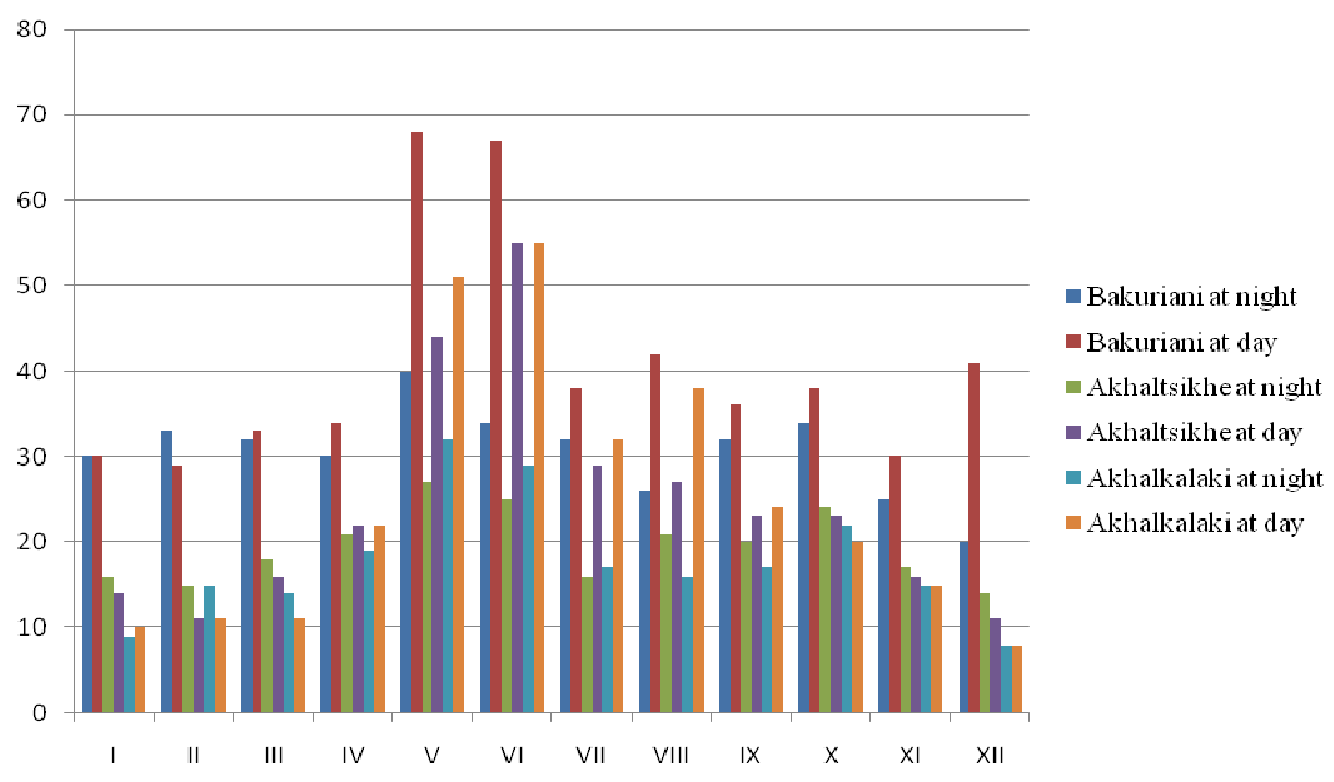

Figure 3. Annual distribution of precipitations during the day and at night.

Table 4. Dates of appearance and disappearance of a snow cover.

\begin{tabular}{|c|c|c|c|c|c|c|c|c|c|c|}
\hline \multirow[t]{2}{*}{ Station } & \multirow{2}{*}{$\begin{array}{l}\text { Daily quantity of } \\
\text { snow cover }\end{array}$} & \multicolumn{3}{|c|}{ The date of snow cover creation } & \multicolumn{3}{|c|}{$\begin{array}{l}\text { The date of stable snow cover } \\
\text { creation }\end{array}$} & \multicolumn{3}{|c|}{$\begin{array}{l}\text { The date of stable snow cover } \\
\text { melting }\end{array}$} \\
\hline & & Average & Early & Late & Average & Early & Late & Average & Early & Late \\
\hline Aspindza & 54 & $2 \mathrm{XII}$ & $24 X$ & $13 \mathrm{I}$ & - & $22 \mathrm{XI}$ & - & - & - & 25. III \\
\hline Akhaltsikhe & 63 & 4. XII & $1 \mathrm{X}$ & $24 \mathrm{I}$ & 24 XII & $22 \mathrm{XI}$ & - & 3 III & - & $30 \mathrm{III}$ \\
\hline Akhalkalaki & 101 & $12 \mathrm{XI}$ & $2 X$ & $1 \mathrm{I}$ & $15 \times 11$ & $2 \mathrm{X} 1$ & - & 12 III & - & $15 \mathrm{IV}$ \\
\hline Abastumani & 101 & $17 \mathrm{IX}$ & $27 \mathrm{IX}$ & $10 \mathrm{I}$ & 16 XII & $11 \mathrm{XI}$ & - & 17 III & - & $9 \mathrm{IV}$ \\
\hline Adigeni & 69 & $25 \mathrm{XI}$ & $1 \mathrm{X}$ & 4 III & 24 XII & $22 \mathrm{XI}$ & - & 7 III & - & 27 III \\
\hline Efremovka & 153 & $29 X$ & $17 \mathrm{IX}$ & $26 \mathrm{XI}$ & $26 \mathrm{XI}$ & $1 \mathrm{XI}$ & $1 \mathrm{I}$ & $21 \mathrm{IV}$ & 25 III & $4 \mathrm{~V}$ \\
\hline Likani & 128 & $24 \mathrm{XI}$ & - & - & $6 \mathrm{XII}$ & _ & _- & $4 \mathrm{IV}$ & - & _- \\
\hline Bakuriani & 143 & $30 \mathrm{X}$ & $13 \mathrm{IX}$ & 10 XII & $5 \mathrm{XII}$ & $31 X$ & 12 II & $14 \mathrm{IV}$ & 17 III & $\overline{7} \mathrm{~V}$ \\
\hline Kartsakhi & 91 & $18 \mathrm{IX}$ & - & - & 19 XII & - & - & 16 III & - & - \\
\hline Rodionovka & 153 & $25 X$ & - & - & $1 \mathrm{XII}$ & - & - & $15 \mathrm{IV}$ & - & - \\
\hline
\end{tabular}


Table 5. Height of a snow cover in the last days of decades, $\mathrm{cm}$.

\begin{tabular}{|c|c|c|c|c|c|c|c|c|}
\hline Station & & Bakuriani & Bakhmaro & Adigeni & Akhaltsikhe & Rodionovka & Efremovka & Abastumani \\
\hline \multirow{3}{*}{ XI } & 2 & & 30 & - & - & - & - & - \\
\hline & 3 & 17 & 69 & - & - & - & - & - \\
\hline & 1 & 20 & 89 & - & - & 8 & 14 & - \\
\hline \multirow[t]{3}{*}{ XII } & 2 & 23 & 105 & - & - & 9 & 18 & 11 \\
\hline & 3 & 25 & 128 & - & 10 & 10 & 22 & 16 \\
\hline & 1 & 26 & 137 & - & 13 & 11 & 30 & 21 \\
\hline \multirow[t]{3}{*}{ I } & 2 & 35 & 149 & - & 14 & 15 & 35 & 22 \\
\hline & 3 & 36 & 189 & 19 & 19 & 22 & 42 & 29 \\
\hline & 1 & 46 & 213 & 21 & 17 & 23 & 44 & 31 \\
\hline \multirow[t]{3}{*}{ II } & 2 & 47 & 220 & 14 & 16 & 29 & 45 & 30 \\
\hline & 3 & 51 & 242 & 12 & 12 & 31 & 53 & 29 \\
\hline & 1 & 50 & 237 & 10 & - & 35 & 57 & 22 \\
\hline \multirow[t]{3}{*}{ III } & 2 & 49 & 246 & - & - & 32 & 58 & 19 \\
\hline & 3 & 37 & 213 & - & - & 19 & 53 & - \\
\hline & 1 & 17 & 173 & - & - & - & 41 & - \\
\hline \multirow[t]{2}{*}{ IV } & 2 & - & 137 & - & - & - & 22 & - \\
\hline & 3 & - & 94 & - & - & - & - & - \\
\hline V & 1 & - & 48 & - & - & - & - & - \\
\hline \multirow{3}{*}{$\begin{array}{l}\text { Highest } \\
\text { valuein the } \\
\text { winter }\end{array}$} & Average & 63 & 272 & 35 & 26 & 40 & 62 & 40 \\
\hline & Max & 108 & 519 & 95 & 63 & 73 & 86 & 71 \\
\hline & Min & 34 & 129 & 16 & 8 & 10 & 31 & 7 \\
\hline
\end{tabular}

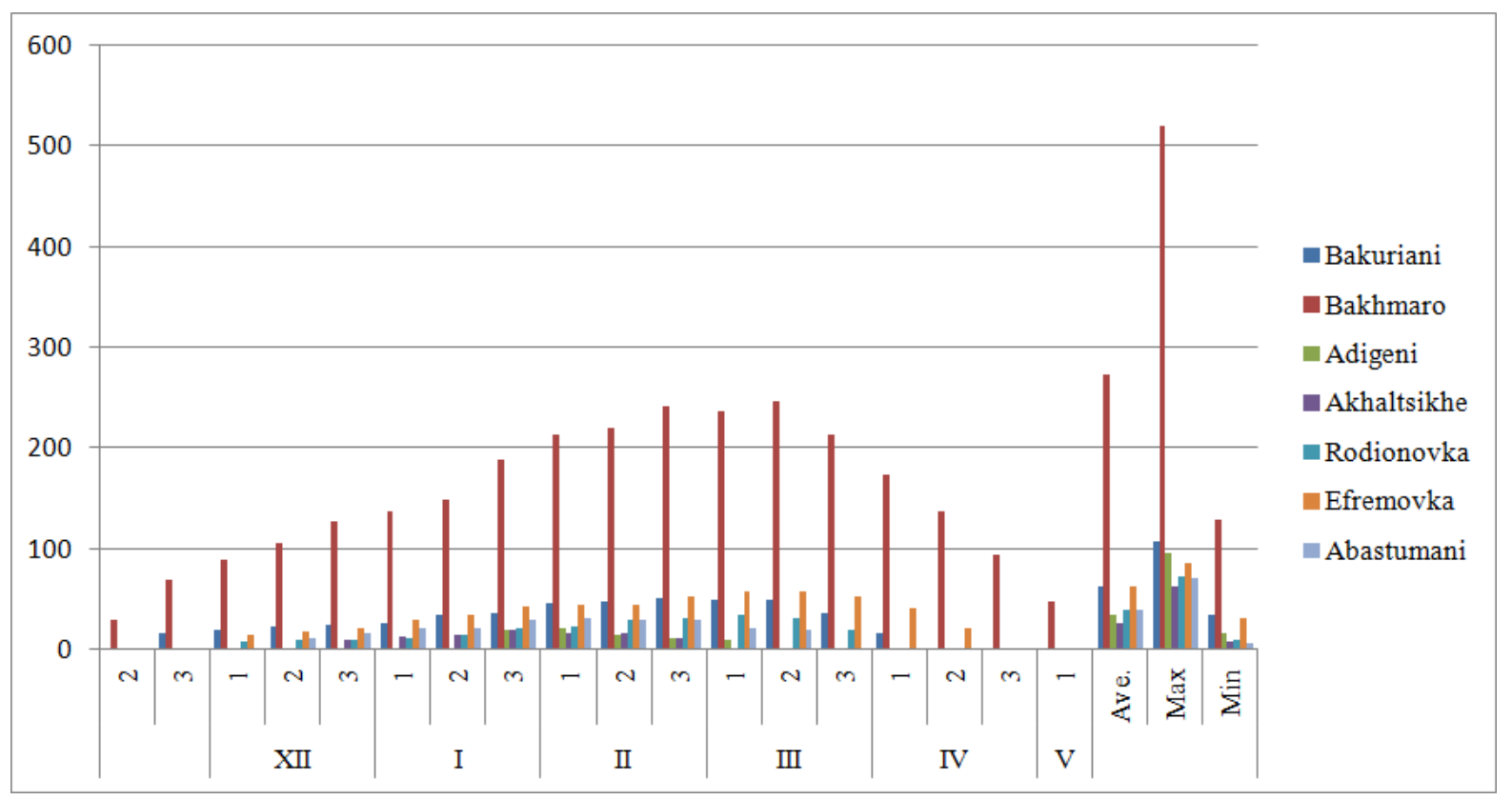

Figure 4. Height of a snow cover in the last days of decades, $\mathrm{cm}$.

The number of days with a snow cover in the region varies from 60 to 160 . The water content in the snow cover varies, and is minimal at the beginning of winter. The more the height and density of a snow cover is, the more the water supply in it is. The water content in a snow cover reaches its maximum value at the moment when the snow starts melting. In winter, the water content in the snow cover varies greatly in different years.

Density is an important property of a snow cover. Heat conductivity and water content in the snow cover, interesting in respect of agriculture, flow registration, etc., vary depending on the density. The density of the snow cover in the region varies within the limits of $0.20-0.24 \mathrm{~g} / \mathrm{cm}^{3}$ [11].

\section{Conclusions}

1. The atmospheric processes on the territory of SamtskheJavakheti are resulted from the geographical location and complex orographic conditions of the region.

2. Arsiani and Ajara-Imereti ridges form an important orographic barrier in Samtskhe-Javakheti region hampering the spread of humid air masses from the west. As a result, the amount of precipitations in the region is little.

3. The total annual amount of precipitations fallen on the territory of Samtskhe-Javakheti varies from 400 to 1400 $\mathrm{mm}$. It is minimal on Javakheti Plateau and in 
Akhaltsikhe basin and is maximal in the highmountainous zone of Adjara-Imereti and Arsiani ridges.

4. A continental type of the annual distribution of precipitations dominates all over the territory of the given region [11]. The least precipitations fall in winter, with the minimum value in January $(24-62 \mathrm{~mm})$ and most precipitations fall in summer, with the maximum value in June $(73-116 \mathrm{~mm})$. The second minimum is fixed in September $(34-55 \mathrm{~mm})$ and the second maximum is fixed in October (41-62 $\mathrm{mm})$.

5. The amount of precipitations in the region falling in the warm period of the year changes from 380 to $621 \mathrm{~mm}$ and from 140 to $328 \mathrm{~mm}$ in the cold period.

6 . The duration of precipitations in summer is reduced by convectional processes with resultant short downpours. On the other hand, frequent cyclonic penetrations in cold period of the year much increase the duration of the precipitations.

7. The number of days with a snow cover in the region varies from 60 to 160 . The water content in the snow cover varies, and is minimal at the beginning of winter. The more the height and density of a snow cover is, the more the water supply in it is. The water content in a snow cover reaches its maximum value at the moment when the snow starts melting. During the year, the water content in the snow cover varies greatly.

8. In winter, density is an important property of a snow cover. Heat conductivity and water content in the snow cover, interesting in respect of agriculture, flow registration, etc., vary depending on the density. The density of the snow cover in the region varies within the limits of $0.20-0.24 \mathrm{~g} / \mathrm{cm}^{3}$.

9. Atmospheric precipitations are a principal climatic element determining the water balance in the area. A complex relief, lateral direction of the ridges and near location of the seas totally transform the atmospheric circulation dominating in the region (the thermal influence of the Black Sea is quite diminished by Meskheti ridge) resulting in the continental nature of the precipitation distribution.

\section{Acknowledgement}

This study is funded by Shota Rustaveli National Science Foundation within the scope of grant "Landscape-ecological evaluation of Samtskhe-Javakheti with GIS analysis for territorial planning" (\#AR/105/9-280/13).

\section{References}

[1] L. Matchavariani, L. Lagidze. Environment Transformation in Georgia as a result of Climate Change. Environment and Ecology in the Mediterranean Region. Chapter 35, Cambridge Scholars Publishing, ISBN(10):1-4438-3757-1, ISBN(13): 978-1-4438-3757-6. UK, 2012, 379-393

[2] B. Beritashvili, N. Kapanadze, I. Chogovadze, Global Warming response Grades of Georgia Climate Change, Tbilisi, 2010, 176 p.

[3] Geography of Georgia, Part I., Tbilisi, Metsniereba, 2000, 314 p.

[4] G. Meladze, Agrometeorology, Tbilisi, Ganatleba, 2008, 248 p.

[5] Sh. Javakhishvili, Climatography of Georgia, Tbilisi, 1977, TSU Publishing House, $237 \mathrm{p}$.

[6] M. Kordzakhia, Climate of Georgia, Tbilisi, Publishing House of the Academy of Sciences of the Georgian 1961, 247 p.

[7] Sh. Javakhishvili, Climate of Meskhet-Javakheti, Tbilisi, TSU Publishing House, 1990, 65 p.

[8] E. Napetvaridze, Atmospheric circulation processes on the territory of Georgia, as a climatic factor, The Works of Vakhushti Institute of Geography, v. 3, Tbilisi, 1984, p.184-193.

[9] Sh. Javakhishvili, Description of the climate in Georgia in different months, Tbilisi, 1988, Ganatleba, 157 p.

[10] Sh. Javakhishvili, Climatology, TSU Publishing House, 1992, $184 \mathrm{p}$.

[11] Sh. Javakhishvili, Atmospheric precipitations on the territory of Georgia, Tbilisi, Metsniereba, 1981, 183 p. 